\title{
A case of hypomagnesaemia due to malabsorption, unresponsive to oral administration of magnesium glycerophosphate, but responsive to oral magnesium oxide supplementation
}

Introduction - Oral and intravenous replacement of minerals such as magnesium and calcium are usually straightforward in clinical practice, the choice generally being governed by the preparation most readily available. There are very few data comparing efficacy and absorption profiles of different magnesium salts. This case report highlights the importance of considering alternative preparations of oral magnesium salts in patients who appear unresponsive to one preparation, rather than moving on to chronic intravenous therapy via a Hickman line. In the case of patients with small bowel shortening, the use of magnesium oxide should be considered.

Case report-A 39 year old Jamaican woman presented with a three day history of paraesthesia and cramps in her hands and feet. Her past medical history included an emergency laparotomy for a septic abortion resulting in extensive resection of both the small and large bowel, ileostomy formation, a left nephrectomy, and a hysterectomy. This surgery had been performed 15 months previously in Jamaica. She had recently begun to pass increasing volumes of liquid secretions into her ileostomy, up to 4-8 litres/day.

On examination she was clinically dehydrated with positive Trousseau's and Chovstek's signs but neurological examination was otherwise normal. The stoma was functioning but copious amounts of clear stomal fluids were noted to be pouring from it. Initial blood tests revealed a normochromic normocytic anaemia (haemoglobin $11.8 \mathrm{~g} / \mathrm{dl}$ ). Renal function was abnormal (sodium $140 \mathrm{mmol} / 1$, potassium $3.2 \mathrm{mmol} / 1$, urea $9.5 \mathrm{mmol} / 1$, creatinine $248 \mathrm{nmol} / \mathrm{l}$ ) and she had a low corrected calcium (1.9 mmol/l), magnesium $(0.13 \mathrm{mmol} / \mathrm{l})$, and albumin $(32 \mathrm{~g} / \mathrm{l})$. Liver function tests were within normal limits. Urinary magnesium was $<0.1 \mathrm{mmol} / 1$ on two occasions.

She was admitted, rehydrated with intravenous crystalloids, and given intravenous magnesium, initially at a dose of $60 \mathrm{mmol} / \mathrm{day}$, and oral calcium supplementation. Her serum calcium normalised with this treatment and renal function returned to a stable baseline (creatinine 140-150 $\mathrm{nmol} / \mathrm{l})$. In view of the large volumes of fluid (4-8 litres/day) passing through her ileostomy, and after an enteral infection had been excluded, she was treated with loperamide, codeine phosphate, WHO rehydration powders, and a low residue diet. This resulted in a reduction in her ileostomy output to 2-3 litres by week 3 of her admission.

Magnesium supplementation was given by increasing oral doses of magnesium glycerophosphate, to a maximum of three $95 \mathrm{mg}$ tablets nine times a day, equivalent to 108 $\mathrm{mmol} / \mathrm{l}$ of magnesium. This failed to maintain adequate serum magnesium concentrations, despite observation by staff on the ward that the patient ingested all the tablets each day. She required intravenous magnesium "top ups" on days $1,6,10,16,18,23,36$, and 40 as a result of repeated episodes of symptomatic hypomagnesaemia. Six weeks after admission there was concern that she may require lifelong intravenous magnesium supplementations.

However, a different magnesium preparation, magnesium oxide, was then substituted as there have been anecdotal reports of its efficacy. ${ }^{12}$ The patient's serum

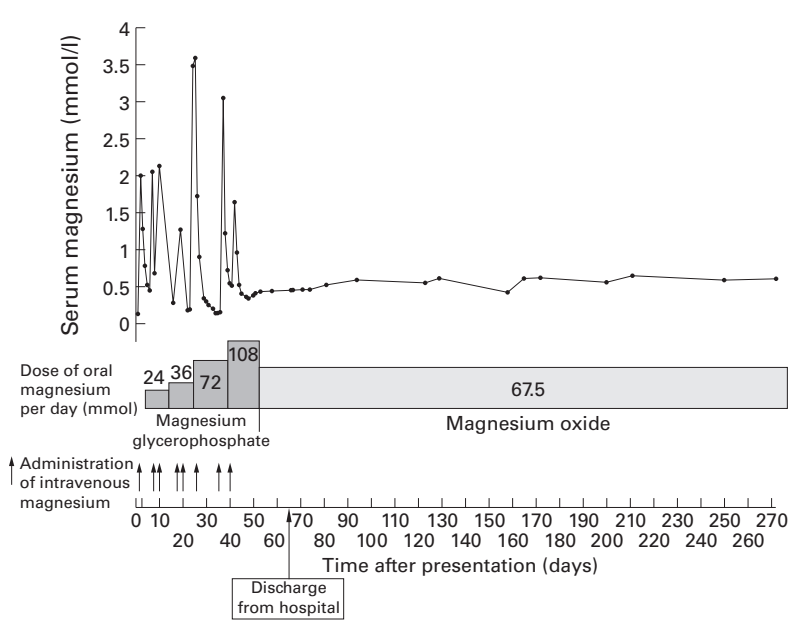

Figure 1 Serum magnesium and dose/preparation of magnesium replacement.

magnesium subsequently stabilised at $0.58 \mathrm{mmol} / \mathrm{l}$ with a dose of three $100 \mathrm{mg}$ tablets nine times a day of magnesium oxide, equivalent to $67.5 \mathrm{mmol}$ of magnesium per day. She was then discharged home on this regimen.

After discharge from hospital, her serum magnesium initially remained stable between 0.58 and $0.62 \mathrm{mmol} / 1$, and she was asymptomatic. However, 14 weeks later she decided to reduce her magnesium oxide intake to two tablets four times a day and her serum magnesium fell to $0.42 \mathrm{mmol} / 1$ (fig 1); this responded quickly when we prompted her to restart the original dose of three tablets nine times a day. Figure 1 demonstrates changes in serum magnesium concentration with time, together with her corresponding doses and preparations of oral magnesium.

Discussion-Magnesium is an essential element and deficiency is rarely encountered in normal individuals but its presence usually indicates underlying disease such as short bowel syndrome. ${ }^{3}$ Magnesium deficiency is a known complication of extensive bowel resection ${ }^{1}$ and this was the most likely cause in our patient as renal loss was found to be minimal. The daily requirement for magnesium has been estimated to be up to $15 \mathrm{mmol} /$ day. $^{4}$ Only one third to a half of ingested magnesium is absorbed, and the site of maximal absorption appears to be the small intestine, mainly the distal part of the ileum. ${ }^{5}$ The fraction of magnesium absorbed increases as magnesium intake decreases. ${ }^{5}$

Our patient failed to maintain serum magnesium levels when taking $108 \mathrm{mmol} /$ day of a standard magnesium preparation, magnesium glycerophosphate. However, she stabilised on $67.5 \mathrm{mmol} /$ day of the magnesium oxide supplementation. The ability of the patient to absorb and/or retain magnesium seems to have been dependant on the preparation.

The most common magnesium salts used to maintain magnesium levels, after intravenous replacement has been given, are the glycerophosphate, oxide, acetate, citrate, phosphate, aspartate, hydroxide, and lactate salts. ${ }^{6}$ There is little evidence comparing the relative bioavailability of 
these different preparations. The British National Formulary currently recommends magnesium glycerophosphate tablets in a dose of $24 \mathrm{mmol}$ daily in divided doses, ${ }^{7}$ but this preparation is not licensed. Administration of magnesium sulphate leads to diarrhoea and magnesium chloride is very hygroscopic and therefore difficult to formulate. ${ }^{8}$ Magnesium aspartate and acetate ${ }^{1}$ are used elsewhere in Europe. Magnesium hydroxide and oxide have anecdotally been reported to be efficacious in case reports, ${ }^{8}$ magnesium oxide was used in 12 patients who had undergone intestinal shunts for obesity, ${ }^{1}$ and magnesium hydroxide was effective in patients with renal calculi. ${ }^{2}$

Three studies have attempted to estimate the absorption of magnesium oxide using urinary excretion data, but none in patients with short bowel syndrome. ${ }^{29}{ }^{10}$ Lindberg and colleagues $^{2}$ studied 17 normal volunteers who underwent three oral loading tests in random order: magnesium citrate (25 mmol), magnesium oxide $(25 \mathrm{mmol})$, or distilled water. The increment in serum magnesium over four hours following loading was higher with the citrate than the oxide: 0.063 (0.135) versus 0.014 (0.007) $\mathrm{mmol} / \mathrm{l}$. Muhlbauer and colleagues, ${ }^{9}$ using a similar technique, found magnesium oxide capsules had lower cumulative magnesium urinary excretion than L-aspartate HCL tablets in eight healthy volunteers but plasma magnesium levels remained unchanged after treatment. Altura and colleagues $^{10}$ studied 18 male volunteers who were given magnesium enriched diets and then $12.34 \mathrm{mmol}$ of magnesium as oxide or phosphate plus oxide, and found that the magnesium oxide preparation improved serum magnesium in those with low basal serum levels but not in those with normal/high serum levels, although again total magnesium remained the same.

We do not know why magnesium oxide was much better absorbed than magnesium glycerophosphate in our patient. It may be that magnesium oxide is better absorbed than magnesium glycerophosphate in patients with a shortened small bowel and hence malabsorption, but the comparative absorption kinetics have never been studied in such patients. However, switching magnesium preparations in this patient and subsequent stabilisation of her serum magnesium level enabled her to avoid insertion of a permanent Hickman line for lifelong intravenous magnesium, and all the associated complications. ${ }^{11}$ Until the absorption kinetics are further elucidated we would recommend consideration of magnesium oxide for supplementation in patients, particularly those with short bowel syndrome and limited absorption, who fail to respond to magnesium glycerophosphate or indeed other preparations. Clearly, compliance is a potential issue but we do not believe this to be the reason for the apparently different efficacy of the magnesium preparations given to our patient.

J R ROSS

P I DARGAN

A L JONES

Department of Medicine, Guy's and St Thomas' Hospital Trust,

Guy's Hospital, London SE1 9RT, UK

A KOSTRZEWSKI

Department of Pharmacy, Guy's and St Thomas' Hospital Trust, Guy's Hospital, London SE1 9RT, UK

Correspondence to: Dr J R Ross, SpR Palliative Medicine, St. Joseph's Hospice, Mare Street, London E8 4SA, UK. joy.ross@talk21.com

Hallberg D. Magnesium problems in gastroenterology. Acta Med Scand 1982;661 (suppl):19-20

2 Lindberg JS, Zobitz MM, Poindexter JR, et al. Magnesium bioavailability from magnesium citrate and magnesium oxide. 7 Am Coll Nutr 1990;9:4855 .

3 Seeling MS. The requirement of magnesium by normal adults summary and analysis of published data. Am f Clin Nutr 1964:14;342-90.

4 Wester PO, Dyckner T. The importance of the magnesium ion. Magnesium deficiency-symptomatology and occurrence. Acta Med Scand 1982; 661 (suppl): $3-4$.

5 Rude KR. Magnesium metabolism and deficiency. Endocrinol Metab Clin North Am 1993;22:377-95.

6 Parfitt K, ed. Martindale, the complete drug reference, 32nd edn. London: Parfitt K, ed. Martindale, the
Pharmaceutical Press, 1999.

7 British National Formulary, 38th edn. London: BMA and Royal PharmaceuBritish National Formulary, 38th edn. Lon
tical Society of Great Britain, 1999:425.

8 Nyhlin H, Dyckner T, Ek B, et al. Magnesium in Crohn's disease. Acta Med Scand 1982;661(suppl):21-5.

9 Muhlbauer B, Schwenk M, Coram WM, et al. Magnesium-L-aspartateHCL and magnesium-oxide: bioavailability in healthy volunteers. Eur $\mathcal{F}$ Clin Pharmacol 1991;40:437-8.

10 Altura BT, Wilimzig C, Trnovec $\mathrm{T}$, et al. Comparative effects of a Mg-enriched diet and different orally administered magnesium oxide preparations on ionized $\mathrm{Mg}, \mathrm{Mg}$ metabolism and electrolytes in serum of human volunteers. 7 Am Coll Nutr 1994:13:447-54.

11 Graham DR, Keldermans MM, Klemm LW, et al. Infectious complications among patients receiving home intravenous therapy with peripheral, central or peripherally placed central venous catheters. Am f Med 1991;91:95or periph. 